\title{
"Let the data do the talking: Empirical modelling of survey-based expectations by means of genetic programming"
}




\title{
${ }_{B}^{\mathbb{O}} \mathrm{I}|\mathrm{R}| \mathrm{E}|\mathrm{A}|$
}

Institut de Recerca en Economia Aplicada Regional i Públic

Research Institute of Applied Economics

WEBSITE: www.ub-irea.com•CONTACT: irea@ub.edu

\section{AQR}

\author{
Grup de Recerca Anàlisi Quantitativa Regional \\ Regional Quantitative Analysis Research Group \\ WEBSITE: www.ub.edu/aqr/•CONTACT: aqr@ub.edu
}

\section{Universitat de Barcelona}

Av. Diagonal, $690 \cdot 08034$ Barcelona

The Research Institute of Applied Economics (IREA) in Barcelona was founded in 2005, as a research institute in applied economics. Three consolidated research groups make up the institute: AQR, RISK and GiM, and a large number of members are involved in the Institute. IREA focuses on four priority lines of investigation: (i) the quantitative study of regional and urban economic activity and analysis of regional and local economic policies,

(ii) study of public economic activity in markets, particularly in the fields of empirical evaluation of privatization, the regulation and competition in the markets of public services using state of industrial economy, (iii) risk analysis in finance and insurance, and (iv) the development of micro and macro econometrics applied for the analysis of economic activity, particularly for quantitative evaluation of public policies.

IREA Working Papers often represent preliminary work and are circulated to encourage discussion. Citation of such a paper should account for its provisional character. For that reason, IREA Working Papers may not be reproduced or distributed without the written consent of the author. A revised version may be available directly from the author.

Any opinions expressed here are those of the author(s) and not those of IREA. Research published in this series may include views on policy, but the institute itself takes no institutional policy positions. 


\section{Abstract}

In this study we use agents' expectations about the state of the economy to generate indicators of economic activity in twenty-six European countries grouped in five regions (Western, Eastern, and Southern Europe, and Baltic and Scandinavian countries). We apply a data-driven procedure based on evolutionary computation to transform survey variables in economic growth rates. In a first step, we design five independent experiments to derive the optimal combination of expectations that best replicates the evolution of economic growth in each region by means of genetic programming, limiting the integration schemes to the main mathematical operations. We then rank survey variables according to their performance in tracking economic activity, finding that agents' "perception about the overall economy compared to last year" is the survey variable with the highest predictive power. In a second step, we assess the out-of-sample forecast accuracy of the evolved indicators. Although we obtain different results across regions, Austria, Slovakia, Portugal, Lithuania and Sweden are the economies of each region that show the best forecast results. We also find evidence that the forecasting performance of the survey-based indicators improves during periods of higher growth.

\section{JEL classification: C51, C55, C63, C83, C93.}

Keywords: Economic indicators, Qualitative survey data, Expectations, Symbolic regression, Evolutionary algorithms, Genetic programming.

Oscar Claveria. AQR-IREA, Universitat de Barcelona, Av. Diagonal 690, 08034 Barcelona, Spain. E-mail: oclaveria@ub.edu

Enric Monte. Department of Signal Theory and Communications, Polytechnic University of Catalunya. E-mail: enric.monte@upc.edu

Salvador Torra. Riskcenter-IREA, Department of Econometrics, Statistics and Applied Economics, University of Barcelona. E-mail: storra@gmail.com

\section{Acknowledgements}

This research was supported by by the projects ECO2016-75805-R and TEC2015-69266-P from the Spanish Ministry of Economy and Competitiveness. We also wish to thank Johanna Garnitz and Klaus Wohlrabe at the IFO Institute for Economic Research in Munich for providing us the data used in the study. 


\section{Introduction}

Agents' expectations about the state of the economy are instrumental for economic modelling. Business and consumer surveys, also known as tendency surveys, are directly addressed to economic agents as a means to measure their expectations. Respondents are asked about the expected direction of change of a wide range of variables (capital expenditures, private consumption, exports, imports, etc.). Accordingly, survey results provide important information about agents' economic expectations, allowing comparisons among different countries' business cycles. Additionally, survey results are available ahead of the publication of quantitative official data, which makes them very useful for monitoring the evolution of the economy.

The fact that survey-based expectations are qualitative in nature has centred research in the development of different approaches to transform survey responses into quantitative measures of agents' expectations. See Driver and Urga (2004), Nardo (2003) and Pesaran and Weale (2006) for a review of methods for the quantification of survey results. Recent developments in empirical modelling have allowed to develop conversion approaches based on evolutionary computation. This study extends previous research by Claveria et al. (2016), who proposed an evolutionary-based two-step procedure to generate estimates of economic growth. The authors derived preliminary building blocks defined as simple combinations of survey variables, and then linearly combined the functions to generate estimates of economic growth in Central and Eastern European economies, finding that the forecasting performance of evolved survey-based indicators could be improved by designing ad-hoc quantification procedures for countries with similar characteristics.

These findings have led us to use evolutionary computation to generate indicators of economic growth that combine different survey variables of 26 European countries grouped into five major European regions (Western, Eastern, and Southern Europe, and Baltic and Scandinavian countries). First, we design five independent experiments that link survey expectations to economic growth, limiting the preliminary functions to the main mathematical operations with the aim of facilitating the implementation of the economic indicators. Once we obtain the optimal combination of survey variables that best replicates the evolution of economic activity in each region, we rank the expectations according to the relative weight of each one in the evolved indicators. In a second step, 
we assess the out-of-sample forecast accuracy of the obtained economic indicators country by country.

Some of the features of empirical modelling are particularly indicated to deal with the problem at hand. First, empirical modelling is especially suitable for finding patterns in large data sets with little or no prior information about the system. Second, empirical modelling allows us to simultaneously evolve both the structure and the parameters of the model without imposing any assumptions regarding agents' expectations. In a recent study, Lahiri and Zhao (2015) found significant improvements in the forecasting performance of quantified expectations when relaxing the assumptions of quantification methods of qualitative survey data.

The empirical modelling approach applied in this research is based on symbolic regression (SR) via genetic programming (GP), which was developed by Koza (1992). While SR is a modelling approach characterised by the search of the space of mathematical expressions that best fit a given dataset, GP is a soft computing search technique for problem-solving (Cramer, 1985). GP is based on the implementation of genetic algorithms (GAs), which are a specific type of evolutionary algorithm (EA). Evolutionary computation can be regarded as a subfield of artificial intelligence, and is being increasingly applied to automated problem solving in economics.

The main aim of this study is twofold. On the one hand, we implement GP to find the optimal combinations of survey expectations to forecast economic growth at a regional level, restricting the integration schemes to the main four mathematical operations so as to obtain easily replicable expressions. This allows us to rank survey variables according to their predictive capacity. On the other hand, we assess the forecasting performance of the evolved economic indicators in each country and compare it to a benchmark model.

The structure of the paper is as follows. The next section reviews the existing literature. In Section 3 we present the methodological approach, describing the data and the experimental set-up. Empirical results are provided in Section 4. Finally, conclusions are drawn in Section 5.

\section{Literature review}

Economic expectations have been widely studied (Pesaran, 1987; Visco, 1984; WrenLewis, 1986). Tendency surveys ask respondents whether they expect a variable to rise, 
to remain constant, or to fall. The relationship between quantitative data and survey results was first formalised by Anderson (1952), who regressed the actual average percentage change of an aggregate variable on the percentage of respondents expecting a variable to rise and to fall. Carlson and Parkin (1975) developed the theoretical framework for quantifying survey expectations by assuming that respondents report a variable to go up if the mean of their subjective probability distribution lies above a threshold level, also known as indifference interval (Theil, 1952).

This relationship has been also explored by matching individual responses with firmby-firm realisations, both empirically (Lahiri and Zhao, 2015; Lui et al., 2011a, b; Mitchell et al., 2002, 2005a, b; Mokinski et al., 2015; Müller, 2010; Zimmermann, 1997), and experimentally by means of Monte Carlo simulations (Claveria et al., 2006; Nardo, 2003). Common (1985) used experimental expectations to test the rational expectations hypothesis. Simulation experiments have also been used to assess the forecasting performance of different quantification methods of survey expectations (Claveria, 2010; Löffler, 1999; Nardo and Cabeza-Gutés, 1999; Terai, 2009).

The link between survey expectations and quantitative data at the aggregate level has been further and widely investigated (Abberger, 2007; Balcombe, 1996; Batchelor, 1981, 1982, 1986; Bennett, 1984; Bergström, 1995; Berk, 1999; Białowolski, 2016; Bovi, 2016; Breitung and Schmeling, 2013; Claveria et al., 2007; Franses et al., 2011; Ghonghadze and Lux, 2012; Graff, 2010; Guizzardi and Stacchini, 2015; Lahiri and Teigland, 1987; Martinsen et al., 2014; Mittnik and Zadrozny, 2005; Nolte and Pohlmeier, 2007; Paloviita, 2006; Pesaran, 1985; Robinzonov et al., 2012; Seitz, 1988; Smith and McAleer, 1995; Vermeulen, 2014). These studies use a wide range of econometric techniques, but none of them assesses the relationship between both types of data by means of evolutionary methods.

In this study we fill this gap by linking survey data and economic growth by means of evolutionary computation. This approach is based on the implementation of GAs, which adopt Darwinian principles of the theory of natural selection in the context of expensive optimisation (Fogel et al., 1966). GAs are the most common type of EA, and were initially proposed by Holland (1975). GP allows the model structure to vary during the evolution, which makes it particularly indicated for non-linear and empirical modelling. See Banzhaf et al. (2008), Dabhi and Chaudhary (2015) and Poli et al. (2010) for a review of the state of the art in GP. 
Most economic applications of evolutionary computing are in finance (Chen and Kuo, 2002; Fogel, 2006; Goldberg, 1989). GAs have been used to predict the financial failure of firms (Acosta-González and Fernández, 2014), to explain the 2008 financial crisis (Acosta-González et al., 2012), to model exchange rates (Lawrenz and Westerhoff, 2003), to evaluate the convergence to the rational expectations equilibrium (Maschek, 2010), to optimize the signals generated by technical trading tools (Thinyane and Millin, 2011), to forecast stock price trends in Taiwan (Wei, 2013), etc. See Drake and Marks (2002) for a review of the applications of GAs in financial forecasting.

Regarding GP, Vasilakis et al. (2013) proposed a GP-based technique to predict returns in the trading of the euro/dollar exchange rate. GP has also been applied to to model short-term capital flows (Yu et al., 2004), to forecast exchange rates (Álvarez-Díaz and Álvarez, 2005), and for stock price forecasting (Chen et al., 2008; Kaboudan, 2000; Larkin and Ryan, 2008; Wilson and Banzhaf, 2009). Wilson and Banzhaf (2009) compared a developmental co-evolutionary GP approach to standard linear GP for interday stock prices prediction. Alexandridis et al. (2017) have recently compared the forecasting performance of GP in the context of weather derivatives pricing with other state-of-the-art machine learning algorithms and classic linear approaches, finding that non-linear methods outperform the alternative linear models significantly.

Up until now there have been very few applications of GP in macroeconomics. The first GP application is that of Koza (1992), who developed GP to find the best single computer program to implement SR. The author used GP to reassess the exchange equation, relating the price level, gross national product, money supply, and the velocity of money. More recent macroeconomic applications of GP have been used with forecasting purposes (Chen et al., 2010; Duda and Szydło, 2011). Ferreria (2011) developed a version of GP known as gene expression programming (GEP). Recently, Peng et al. (2014) proposed an improved GEP algorithm especially suitable for dealing with SR problems. Gandomi and Roke (2015) compared the forecasting performance of artificial neural network models to that of GEP techniques.

$\mathrm{SR}$ is an empirical modelling technique used to construct regression models (form linear regression to radial basis functions, support vector machines, kriging, etc.). Given a predetermined set of operations and functions, SR searches appropriate models from the space of all possible mathematical expressions that best fit the data. Zelinka et al. (2005) introduced analytical programming in order to synthesise suitable solutions in SR. 
Given its versatility, SR has been increasingly used in different areas (Barmpalexis et al., 2011; Cai et al., 2006; Can and Heavey, 2011; Ceperic et al., 2014; Sarradj and Geyer, 2014; Vladislavleva et al., 2010; Wu et al., 2008; Yang et al., 2015; Yao and Lin, 2009; Zameer et al., 2017), but there have been very few SR applications in macroeconomics. Claveria et al. (2016) implemented SR via GP to derive a set of building blocks used to estimate economic activity. Kl'účik (2012) used SR to estimate total exports and imports to Slovakia. Kotanchek et al. (2010) implemented SR via GP to predict economic activity. By means of SR, Kronberger et al. (2011) identified interactions between economic indicators in order to estimate the evolution of prices in the US. The authors suggested using SR for the exploration of variable interplay when approaching complex modelling tasks, as it provides a quick overview of the most relevant interactions and can help to identify new unknown links between variables.

In this study we design five independent SR experiments and apply GP in order to find the optimal combinations of survey expectations that best fit the actual evolution of economic activity.

\section{Data and Methodology}

In this study we use SR via GP to formalize the optimal interactions between survey variables that best allow to predict economic growth, restricting them to the main mathematical operations (addition, subtraction, multiplication, and division). In order to do so, we need to combine two types of information: qualitative survey expectations and quantitative official statistics from 2000:Q2 to 2016:Q3. Regarding the former, we make use of survey data on expectations from the World Economic Survey (WES) carried out by the Ifo Institute for Economic Research. As a proxy of economic activity we use the year-on-year growth rates of the Gross Domestic Product (GDP) retrieved from the Organisation for Economic Co-operation and Development (OECD) (https://data.oecd.org/gdp/quarterly-gdp.htm\#indicator-chart).

The analysis is carried out for 26 European economies grouped in five regions based on the criteria used for statistical processing purposes by the United Nations Statistics Division. As a result, Austria, Belgium, France, Germany, Ireland, the Netherlands and the United Kingdom (UK) are grouped as Western Europe (1); Bulgaria, the Czech Republic, Hungary, Poland, Romania and the Slovak Republic as Eastern Europe (2); Croatia, Greece, Italy, Portugal, Slovenia and Spain as Southern Europe (3); Estonia, 
Latvia and Lithuania as the Baltic countries (4); Denmark, Finland, Norway and Sweden as the Scandinavian countries (5).

In Table 1 we present the twelve survey variables used in the study, denoted as $X_{i t}$, where $i$ refers to each country and $t$ to the time period. Survey variables can be divided in judgements, perceptions and expectations, depending on whether they refer to the expected value in the present, in the present compared to last year, or for the next six months. See Kudymowa et al. (2013), Hutson et al. (2014), and Garnitz et al. (2015) for an appraisal of the WES data.

Table 1. Survey variables

\begin{tabular}{lll}
\hline Judgements & Overall economy & $X 1_{i t}$ \\
Present & Capital expenditures & $X 2_{i t}$ \\
Economic situation & Private consumption & $X 3_{i t}$ \\
\hline Perceptions & Overall economy & $X 4_{i t}$ \\
Compared to last year & Capital expenditures & $X 5_{i t}$ \\
Economic situation & Private consumption & $X 6_{i t}$ \\
\hline Expectations & Overall economy & $X 7_{i t}$ \\
For the next 6 months & Capital expenditures & $X 8_{i t}$ \\
Economic situation & Private consumption & $X 9_{i t}$ \\
\hline Foreign trade volume & Volume of exports & $X 10_{i t}$ \\
& Volume of imports & $X 11_{i t}$ \\
& Trade balance & $X 12_{i t}$ \\
\hline
\end{tabular}

By means of GP we evolve a symbolic expression for each region combining the different survey variables for each country until a stopping criterion is reached. Regarding this criterion, it can either be a predetermined value of the fitness function or a given number of generations. As there is a trade-off between accuracy and simplicity, we have chosen a maximum number of 50 generations as as stopping criterion. In Table 2 we summarize the steps for implementing the experiment in each of the regions.

Table 2. GP implementation - Steps

\begin{tabular}{|c|c|}
\hline 1. Creation of an initial population of programs & 50,000 \\
\hline 2. Evaluation of fitness for each program & Mean absolute error (MAE) \\
\hline 3. Selection of a reproduction strategy & Tournament method (size 3) \\
\hline 4. Application of genetic operators & Mutation probability 0.25 \\
\hline 5. Determination of constants & Automatically generated \\
\hline 6. Creation of a new population & Max. generations 150 \\
\hline
\end{tabular}


Genetic operators (crossover and mutation) are applied to the parents selected on the basis of the fitness function. Crossover consists on the recombination of randomly chosen parts of parents, while mutation on randomly altering a part of a parent. Consequently, the fitness of the population increases generation after generation. The output of this process is a set with the best individual functions from all generations for each region. In this study we have used the open source Distributed Evolutionary Algorithms Package (DEAP) framework implemented in Python (Fortin et al., 2012; Gong et al., 2015).

\section{Results}

In this section we first present the output of the different experiments that were undertaken for each region $(R=1,2,3,4,5)$ for the in-sample period (2000:Q2 to 2014:Q1). The output, $\hat{y}_{R, i t}$, is the evolved expression for each region, and can be seen as the optimal combination of survey variables for each set of countries. Second, we compute the relative frequency with which each survey variable appears in the symbolic economic indicators to determine which survey variables play a major role in tracking the evolution of the economy. Finally, we analyse the predictive performance of the proposed economic indicators in an out-of-sample forecasting comparison. The following evolved symbolic expressions can be regarded as survey-based indicators for each region:

$$
\begin{aligned}
& \hat{y}_{1, i t}=\frac{\left(X 1_{i t}+X 3_{i t}+X 4_{i t}+X 5_{i t}-10\right) X 4_{i t}}{6 X 4_{i t}-5} \\
& \hat{y}_{2, i t}=\frac{1}{10}\left\lfloor X 3_{i t}\left(X 10_{i t}-1\right)-\frac{1}{100}\left\lfloor\frac{X 3_{i t}}{\left.\frac{1}{10}\left[\frac{\left(X 10_{i t}+1\right)-\left(X 4_{i t}-5\right)\left(X 3_{i t}+1\right)}{X 10_{i t}}-1\right]-1\right]}\right\rfloor\right. \\
& \hat{y}_{3, i t}=\frac{X 1_{i t}-5}{0.5 X 11_{i t}+\frac{1}{10}\left(3 X 1_{i t}+X 9_{i t}+X 11_{i t}-1\right)} \\
& \hat{y}_{4, i t}=\frac{1}{10}\left\lfloor\left(5+\frac{X 6_{i t}}{5}-1+X 4_{i t}+X 5_{i t}-X 12_{i t}\right)\right. \\
& \hat{y}_{5, i t}=\frac{1}{10}\left\lfloor X 4_{i t}+\frac{X 3_{i t} X 4_{i t}}{10}-7+\left(X 3_{i t}+X 4_{i t}\right) \frac{X 11_{i t}}{10}+X 3_{i t}\right\rfloor
\end{aligned}
$$


In Table 3 we the compute the relative weight of each survey variable in the evolved indicators.

Table 3. Relative frequency of survey variables

\begin{tabular}{lcccccccccccc}
\hline Region & $X 1_{i t}$ & $X 2_{i t}$ & $X 3_{i t}$ & $X 4_{i t}$ & $X 5_{i t}$ & $X 6_{i t}$ & $X 7_{i t}$ & $X 8_{i t}$ & $X 9_{i t}$ & $X 10_{i t}$ & $X 11_{i t}$ & $X 12_{i t}$ \\
\hline 1 & 1 & 0 & 1 & 1 & 1 & 0 & 0 & 0 & 0 & 0 & 0 & 0 \\
2 & 0 & 0 & 1 & 1 & 0 & 0 & 0 & 0 & 0 & 1 & 0 & 0 \\
3 & 1 & 0 & 0 & 1 & 0 & 0 & 0 & 0 & 1 & 0 & 1 & 0 \\
4 & 0 & 1 & 0 & 1 & 1 & 1 & 0 & 0 & 0 & 0 & 0 & 0 \\
5 & 0 & 0 & 1 & 1 & 0 & 0 & 0 & 0 & 0 & 0 & 1 & 0 \\
\hline $\begin{array}{l}\text { Total } \\
\begin{array}{l}\text { Relative } \\
\text { freq. (\%) }\end{array}\end{array}$ & $\mathbf{2}$ & $\mathbf{1}$ & $\mathbf{3}$ & $\mathbf{5}$ & $\mathbf{2}$ & $\mathbf{1}$ & $\mathbf{0}$ & $\mathbf{0}$ & $\mathbf{1}$ & $\mathbf{1}$ & $\mathbf{2}$ & $\mathbf{1}$ \\
\hline
\end{tabular}

Note: Region 1 stands for Western Europe, 2 for Eastern Europe, 3 for Southern Europe, 4 for Baltic countries, 5 for Scandinavian countries.

We can observe that variable $X 4_{i t}$ (perception of the overall economic situation compared to last year) is by far the variable that more frequently appears in the symbolic expressions, being present in all five evolved indicators. The second most frequent variables is $X 3_{i t}$, which refers to the judgement about the present situation of private consumption. The expectations about the future are the variables with a lower weight, being $X 7_{i t}$ and $X 8_{i t}$ (expectations for the next six months about the overall economy and capital expenditures respectively) the only variables that do not appear in any of the regions.

Next, we analyse the predictive performance of these evolved economic indicators in an out-of-sample forecasting comparison for the period 2014:Q2 to 2016:Q3. With this aim we compute several measures of prediction accuracy. First, the the mean absolute error (MAE), the root mean square error (RMSE), and the mean absolute percentage error (MAPE) in order to assess the predictive content in terms of forecast accuracy. Second, we compute the mean absolute scaled error (MASE) and the percentage of periods with lower absolute error (PLAE) to compare the forecasting performance to a baseline model. 
Let us denote $y_{t}$ as the actual value, and $\hat{y}_{t}$ as forecast at period $t, t=1, \ldots, n$. Forecast errors can then be defined as $e_{t}=y_{t}-\hat{y}_{t}$. We have two competing models $A$ and $B$, where $A$ refers to the forecasting model under evaluation and $B$ stands for benchmark model. Given that there is a delay of more than a quarter between the publication of official quantitative data with regard to survey data, in this study we use two-step ahead naïve forecasts as a baseline. The MASE can then be obtained as the mean of the absolute value of the scaled error $q_{t}$ :

$$
\text { MASE = mean }\left|q_{t}\right| \quad \text { where } q_{t}=e_{t} /\left(\sum_{t=3}^{n}\left|y_{t}-y_{t-2}\right| / n-1\right)
$$

The MASE, proposed by Hyndman and Koehler (2006), allows to scale the forecast errors by the mean absolute in-sample errors obtained with a benchmark model. This statistic presents several advantages over other forecast accuracy measures. On the one hand, it is independent of the scale of the data. On the other hand, it is easy to interpret: values less than one indicate that the average prediction computed with the benchmark model is worse than the estimates obtained with the proposed method.

With the aim of finding an easy to interpret measure to compare the forecast accuracy between two models, Claveria et al. (2015) proposed the PLAE statistic, which is also a dimensionless measure. The PLAE is based on the CJ statistic proposed by Cowles and Jones (1937) for testing market efficiency and the 'percent better' measure proposed by Makridakis and Hibon (2000) to compare the forecast accuracy of the models to a random walk. The PLAE consists on a ratio that calculates the proportion of periods in which the model under evaluation obtains a lower absolute forecasting error than the benchmark model:

$$
P L A E=\frac{\sum_{t=1}^{n} \lambda_{t}}{n} \text { where } \lambda_{t}= \begin{cases}1 & \text { if }\left|e_{t, A}\right|<\left|e_{t, B}\right| \\ 0 & \text { otherwise }\end{cases}
$$

In Table 4 we summarise the information of the different forecast accuracy measures. The best forecasting performance is obtained for Austria and the UK in Western Europe, for Slovakia in Eastern Europe, for Portugal and Spain in Southern Europe, for Lithuania in the Baltic countries, and for Sweden in the Scandinavian countries. If we average the results by region, we obtain the best results for the Baltic and the Scandinavian countries. These results are in line with those of Claveria et al. (2017), who in a similar experiment obtained the lowest MAE and RMSE values for Austria, Belgium, Bulgaria, Estonia, and Lithuania. 
Table 4. Out-of-sample forecast accuracy

\begin{tabular}{|c|c|c|c|c|c|}
\hline & MAE & RMSE & MAPE & MASE & $\operatorname{PLAE}(\%)$ \\
\hline Western Europe & 2.554 & 3.140 & 0.761 & 0.972 & $21 \%$ \\
\hline Austria & 0.498 & 0.581 & 0.663 & 0.264 & $30 \%$ \\
\hline Belgium & 0.952 & 1.072 & 0.672 & 0.543 & $20 \%$ \\
\hline France & 0.818 & 0.926 & 0.918 & 0.492 & $20 \%$ \\
\hline Germany & 1.900 & 1.964 & 1.317 & 1.439 & $0 \%$ \\
\hline Ireland & 11.800 & 15.241 & 0.651 & 3.032 & $20 \%$ \\
\hline NL & 1.110 & 1.309 & 0.743 & 0.627 & $30 \%$ \\
\hline UK & 0.798 & 0.886 & 0.365 & 0.405 & $30 \%$ \\
\hline Eastern Europe & 1.513 & 1.269 & 0.399 & 0.387 & $38 \%$ \\
\hline Bulgaria & 1.188 & 1.295 & 0.481 & 0.374 & $30 \%$ \\
\hline Czechia & 3.146 & 1.469 & 0.402 & 0.442 & $70 \%$ \\
\hline Hungary & 1.323 & 1.596 & 0.722 & 0.655 & $10 \%$ \\
\hline Poland & 1.788 & 1.040 & 0.268 & 0.207 & $50 \%$ \\
\hline Romania & 1.415 & 1.602 & 0.357 & 0.497 & $20 \%$ \\
\hline Slovakia & 0.220 & 0.613 & 0.165 & 0.144 & $50 \%$ \\
\hline Southern Europe & 0.901 & 1.058 & 1.775 & 0.835 & $38 \%$ \\
\hline Croatia & 0.813 & 0.958 & 1.139 & 0.468 & $40 \%$ \\
\hline Greece & 1.051 & 1.356 & 4.551 & 1.465 & $50 \%$ \\
\hline Italy & 0.625 & 0.657 & 3.504 & 1.352 & $20 \%$ \\
\hline Portugal & 0.542 & 0.731 & 0.556 & 0.631 & $60 \%$ \\
\hline Slovenia & 1.213 & 1.352 & 0.512 & 0.514 & $20 \%$ \\
\hline Spain & 1.160 & 1.292 & 0.388 & 0.577 & $40 \%$ \\
\hline Baltic countries & 0.952 & 1.159 & 0.506 & 0.221 & $43 \%$ \\
\hline Estonia & 0.954 & 1.227 & 0.460 & 0.231 & $30 \%$ \\
\hline Latvia & 1.135 & 1.322 & 0.736 & 0.259 & $40 \%$ \\
\hline Lithuania & 0.768 & 0.927 & 0.322 & 0.172 & $60 \%$ \\
\hline Scandinavian countries & 0.900 & 1.068 & 0.738 & 0.491 & $35 \%$ \\
\hline Denmark & 0.646 & 0.822 & 0.809 & 0.524 & $40 \%$ \\
\hline Finland & 0.920 & 1.063 & 1.402 & 0.417 & $20 \%$ \\
\hline Norway & 1.469 & 1.615 & 0.595 & 0.791 & $20 \%$ \\
\hline Sweden & 0.566 & 0.771 & 0.144 & 0.231 & $60 \%$ \\
\hline
\end{tabular}

Finally, we compute the correlation between the evolution of GDP and the estimated growth derived from the evolved economic indicators, differentiating between those periods in which economic growth lies out or within the interquartile range (IQR) of the distribution in the European Union. The IQR, also known as midspread, is a measure of 
statistical dispersion, obtained as the difference between upper and lower quartiles, Q3-Q1. By discriminating between these two states of growth, we can evaluate whether there are differences in the accuracy of the estimates of economic activity across regions. In Fig. 1 we present the boxplots for each region.

Fig. 1. Correlations between GDP and expected GDP within and out of IQR

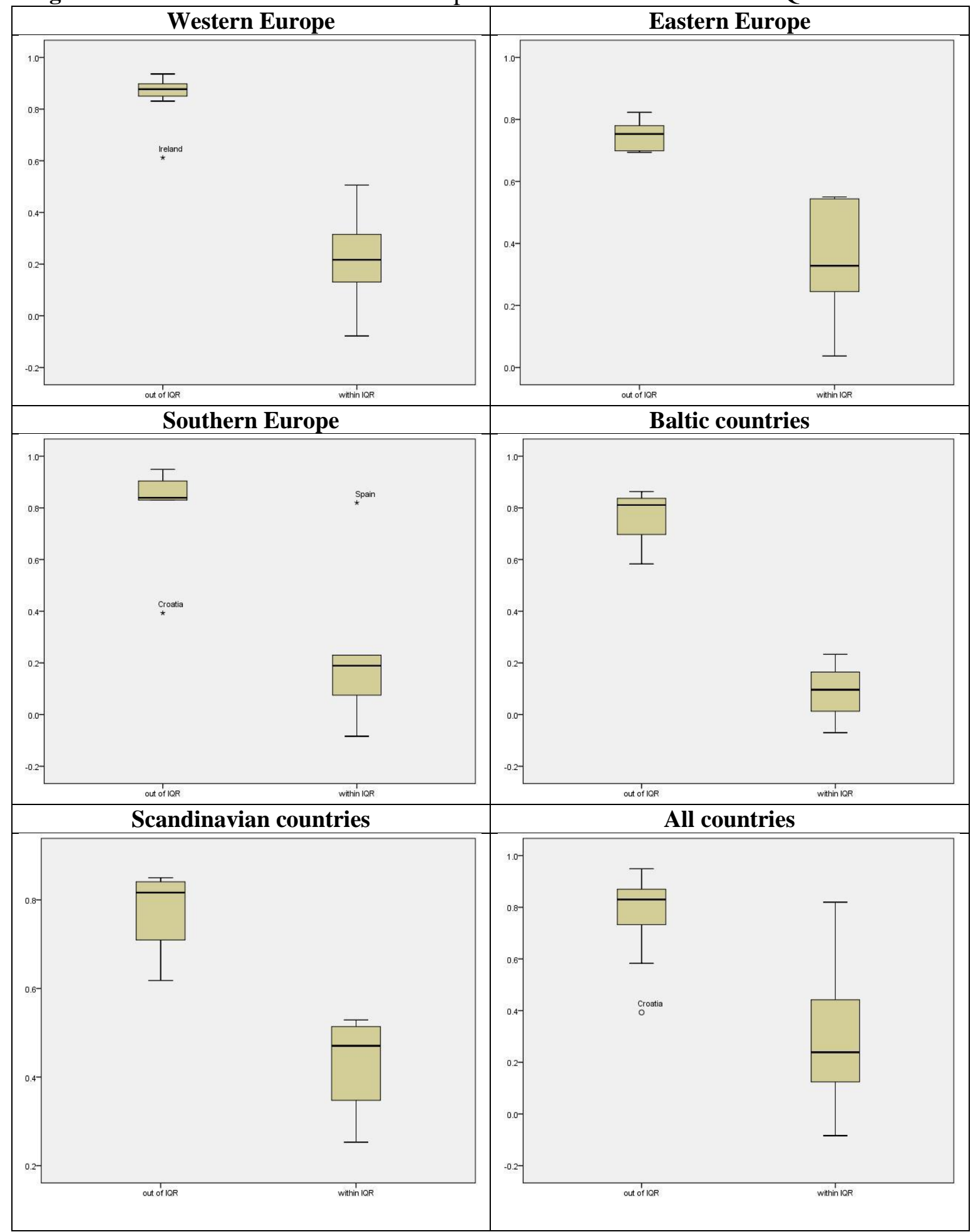

Note: IQR stands for interquartile range. 
In Fig. 1 we can observe that the highest correlations during periods of high growth rates are obtained in Western Europe, with the exception of Ireland. It can also be seen that in all regions the performance of the evolved indicators varies depending on the level of variability: during periods of average growth the correlation between estimates and actual values is lower than during periods of high growth rates. These results are in line with those obtained by Łyziak and Mackiewicz-Łyziak (2014), who found that the 2008 financial crisis period had led to a decrease in expectational errors in transition economies. As noted by Lee (1994), the differences between the actual values of a variable and quantified expectations may arise from three different sources: the measurement or conversion error due to the use of quantification methods, the expectational error due to the agents' limited ability to predict the movements of the actual variable, and the sampling errors. Since survey data are approximations of unobservable expectations, they inevitably entail a measurement error.

In this regard, there is no consensus in the literature about the usefulness of the information content of survey expectations. While some authors have found that quantified expectations fail to capture changes in the analysed quantitative variables (Breitung and Schmeling, 2013; Jonsson and Österholm, 2011, 2012; Lacová and Král, 2015; Lui et al., 2011a, b; Maag, 2009), Altug and Çakmakli (2016), Batchelor and Dua (1992, 1998), Batchelor and Orr (1988), Dees and Brinca (2013), Girardi (2014), Hansson et al. (2005), Ivaldi (1992); Jean-Baptiste (2012), Klein and Özmucur (2010), Leduc and Sill (2013), Lemmens et al. (2005), Müller (2009), Qiao et al. (2009) and Schmeling and Schrimpf (2011) have found evidence regarding the usefulness of survey expectations for economic modelling.

\section{Conclusion}

This paper proposes an empirical modelling approach to design survey-based economic indicators at a regional level. By means of SR via GP we find the optimal combination of survey variables that best tracks the evolution of the economic activity in twenty-six European countries grouped in five regions (Western Europe, Eastern Europe, Southern Europe, Baltic countries and Scandinavian countries). This data-driven approach based on evolutionary computation allows us to transform qualitative survey expectations into quantitative estimates of economic activity. 
We have used survey variables regarding expectations about the economic situation from the World Economic Survey in order to find the most relevant interactions in each region. This exercise allows us to rank the expectations according to the relative weight of each one in the evolved economic indicators. Although results differ across regions, agents" "perception about the overall economy compared to the same time last year" is the best predictor of economic activity.

In a second step, we assess the out-of-sample forecast accuracy of the evolved surveybased indicators in each region. The best forecasting performance is obtained for Austria and the UK in Western Europe, for Slovakia in Eastern Europe, for Portugal in Southern Europe, for Lithuania in the Baltic countries, and for Sweden in the Scandinavian countries. At the regional level we obtain the best results for the Baltic and the Scandinavian countries.

Finally, we evaluate if there are differences in the accuracy of the estimates of economic activity across regions depending on the level of growth. We find that during periods of average growth rates the correlation between estimates and actual values is lower in all regions. The highest correlations during periods of high variability are obtained in Western Europe.

In spite of the novelty of the proposed approach, this research is not without limitations. On the one hand, given that we used a data-driven method, the evolved economic indicators are not grounded in any theoretical background. On the other hand, extending the analysis to other survey data would allow us to examine the extent of the similarities in the derived functional forms. Another issue left for further research is testing whether the implementation of alternative algorithms could improve the forecast accuracy of empirically generated quantitative estimates of expectations.

\section{References}

Abberger, K. (2007). Qualitative business surveys and the assessment of employment - A case study for Germany. International Journal of Forecasting 23(2): 249-258.

Altug, S. and Çakmakli, C. (2016). Forecasting inflation using survey expectations and target inflation: Evidence from Brazil and Turkey. International Journal of Forecasting 32(1): $138-153$.

Acosta-González, E., and Fernández, F. (2014). Forecasting financial failure of firms via genetic algorithms. Computational Economics 43(2): 133-157.

Acosta-González, E., Fernández, F., and Sosvilla, S. (2012). On factors explaining the 2008 financial crisis. Economics Letters 115(2): 215-217. 
Alexandridis, A. K., Kampouridis, M., and Cramer, S. (2017). A comparison of wavelet networks and genetic programming in the context of temperature derivatives. International Journal of Forecasting 33(1): 21-47.

Álvarez-Díaz, M., and Álvarez, A. (2005). Genetic multi-model composite forecast for nonlinear prediction of exchange rates. Empirical Economics 30(3): 643-663.

Anderson, O. (1952). The Business Test of the IFO-Institute for Economic Research, Munich, and its theoretical model. Revue de l'Institut International de Statistique 20: 1-17.

Balcombe, K. (1996). The Carlson-Parkin method applied to NZ price expectations using QSBO survey data. Economics Letters 51(1): 51-57.

Banzhaf, W., Nordin, P., Keller, R. E., and Francone, F. D. (2008). Genetic Programming - An Introduction. On the Automatic Evolution of Computer Programs and its Applications. San Francisco, CA: Morgan Kaufmann.

Barmpalexis, P., Kachrimanis, K., Tsakonas, A., and Georgarakis, E. (2011). Symbolic regression via genetic programming in the optimization of a controlled release pharmaceutical formulation. Chemometrics and Intelligent Laboratory Systems 107(1): $75-82$.

Batchelor, R. A. (1981). Aggregate expectations under the stable laws. Journal of Econometrics 16(2): 199-210.

Batchelor, R. A. (1982). Expectations, output and inflation: The European experience. European Economic Review 17(1): 1-25.

Batchelor, R. A. (1986). Quantitative v. qualitative measures of inflation expectations. Oxford Bulletin of Economics and Statistics 48(2): 99-120.

Batchelor, R. and Dua, P. (1992). Survey expectations in the time series consumption function. The Review of Economics and Statistics 74(4): 598-606.

Batchelor, R. and Dua, P. (1998). Improving macro-economic forecasts. International Journal of Forecasting 14(1): 71-81.

Batchelor, R. and Orr, A. B. (1988). Inflation expectations revisited. Economica 55(2019): 317331.

Bennett, A. (1984). Output expectations of manufacturing industry. Applied Economics 16(6): 869-879.

Bergström, R. (1995). The relationship between manufacturing production and different business survey series in Sweden 1968-1992. International Journal of Forecasting 11(3): 379-393.

Berk, J. M. (1999). Measuring inflation expectations: A survey data approach. Applied Economics 31(11): 1467-1480.

Białowolski, P. (2016). The influence of negative response style on survey-based household inflation expectations. Quality \& Quantity 50(2): 509-528.

Bovi, M. (2016). The tale of two expectations. Quality \& Quantity 50(6): 2677-2705.

Breitung, J. and Schmeling, M. (2013). Quantifying survey expectations: What's wrong with the probability approach? International Journal of Forecasting 29(1): 142-154.

Cai, W., Pacheco-Vega, A., Sen, M. and Yang, K. T. (2006). Heat transfer correlations by symbolic regression. International Journal of Heat and Mass Transfer 49(23-24): 43524359.

Can, B. and Heavey, C. (2011). Comparison of Experimental Designs for Simulation-based Symbolic Regression of Manufacturing Systems. Computers \& Industrial Engineering 61(3): 447-462.

Carlson, J. A. and Parkin, M. (1975). Inflation expectations. Economica 42(166): 123-138.

Ceperic, V., Bako, N. and Baric, A. (2014). A symbolic regression-based modelling strategy of AC/DC rectifiers for RFID applications. Expert Systems with Applications 41(16): 70617067.

Chen, X., Pang, Y. and Zheng, G. (2010). Macroeconomic forecasting using GP based vector error correction model. In J. Wang (Ed.), Business Intelligence in Economic Forecasting: Technologies and Techniques (pp. 1-15). Hershey, PA: IGI Global.

Chen, S. H. and Kuo, T. W. (2002). Evolutionary computation in economics and finance: A bibliography. In S. H. Chen (Ed.), Evolutionary Computation in Economics and Finance (pp. 419-455). Heidelberg: Physica-Verlag. 
Chen, S. H., Kuo, T. W. and Hoi, K. M. (2008). Genetic programming and financial trading: How much about "what we know". In C. Zopounidis et al. (Eds.), Handbook of financial engineering (pp. 99-154). New York: Springer.

Claveria, O. (2010). Qualitative survey data on expectations. Is there an alternative to the balance statistic? In A. T. Molnar (Ed.), Economic Forecasting (pp. 181-190). Hauppauge, NY: Nova Science Publishers.

Claveria, O., Monte, E. and Torra, S. (2015). A new forecasting approach for the hospitality industry. International Journal of Contemporary Hospitality Management 27(7): 1520 1538.

Claveria, O., Monte, E. and Torra, S. (2016). Quantification of survey expectations by means of symbolic regression via genetic programming to estimate economic growth in Central and Eastern European economies. Eastern European Economics 54(2): 177-189.

Claveria, O., Monte, E. and Torra, S. (2017). A new approach for the quantification of qualitative measures of economic expectations. Quality \& Quantity. In Press.

Claveria, O., Pons, E. and Ramos, R. (2007). Business and consumer expectations and macroeconomic forecasts. International Journal of Forecasting 23(1): 47-69.

Claveria, O., Pons, E. and Suriñach, J. (2006). Quantification of expectations. Are they useful for forecasting inflation? Economic Issues 11(2): 19-38.

Common, M. (1985). Testing for rational expectations with qualitative survey data. Manchester School of Economic and Social Statistics 53(2): 138-148.

Cramer, N. (1985). A representation for the adaptive generation of simple sequential programs. Proceedings of the International Conference on Genetic Algorithms and their Applications, 24-26 June. Pittsburgh, PA.

Dabhi, V. K. and Chaudhary, S. (2015). Empirical modeling using genetic programming: A survey of issues and approaches. Natural Computing 14(2): 303-330.

Dees, S. and Brinca, P. S. (2013). Consumer confidence as a predictor of consumption spending: Evidence for the United States and the Euro area. International Economics 134: 1-14.

Drake, A. E. and Marks, R. E. (2002). Genetic algorithms in economics and finance: Forecasting stock market prices and foreign exchange $-\mathrm{A}$ review. In S. H. Chen (Ed.), Genetic Algorithms and Genetic Programming in Computational Finance (pp. 29-54). New York: Springer.

Driver and Urga (2004)

Duda, J. and Szydło, S. (2011). Collective intelligence of genetic programming for macroeconomic forecasting. In P. Jędrzejowicz et al. (Eds.), Computational Collective Intelligence. Technologies and Applications (pp. 445-454). Berlin: Springer.

Ferreira, C. (2001). Gene expression programming: A new adaptive algorithm for solving problems. Complex Systems 13(2): 87-129.

Fogel, D. B. (2006). Evolutionary computation. Toward a new philosophy of machine intelligence (Third Edition). Hoboken, NJ: John Wiley \& Sons.

Fogel, L. J., Owens, A. J. and Walsh, M. J. (1966). Artificial intelligence through simulated evolution. New York: John Wiley.

Fortin, F. A., De Rainville, F. M., Gardner, M. A., Parizeau, M. and Gagné, C. (2012). DEAP: Evolutionary algorithms made easy. Journal of Machine Learning Research 13(1): 21712175.

Franses, P. H., Kranendonk, H. C. and Lanser, D. (2011). One model and various experts: Evaluating Dutch macroeconomic forecasts. International Journal of Forecasting 27(2): $482-495$.

Gandomi, A. H. and Roke, D. (2015). Assessment of artificial neural network and genetic programming as predictive tools. Advances in Engineering Software 88: 63-72.

Garnitz, J., Nerb, G. and Wohlrabe, K. (2015). CESifo World Economic Survey - November 2015. CESifo World Economic Survey 14(4): 1-28.

Girardi, A. (2014). Expectations and macroeconomic fluctuations in the euro area. Economics Letters 125(2): 315-318.

Goldberg, D. E. (1989). Genetic algorithms in search, optimization, and machine learning. Reading Boston, MA: Addison-Wesley. 
Gong, Y. J., Chen, W. N., Zhan, Z. H., Zhang, J., Li, Y., Zhang, Q. and Li, J. J. (2015). Distributed evolutionary algorithms and their models: A survey of the stat-of-the-art. Applied Soft Computing 34: 286-300.

Graff, M. (2010). Does a multi-sectoral design improve indicator-based forecasts of the GDP growth rate? Evidence from Switzerland. Applied Economics 42(21): 2759-2781.

Guizzardi, A. and Stacchini, A. (2015). Real-time forecasting regional tourism with business sentiment surveys. Tourism Management 47: 213-223.

Hansson, J., Jansson, P. and Löf, M. (2005). Business survey data: Do they help in forecasting GDP growth? International Journal of Forecasting 30(1): 65-77.

Holland, J. H. (1975). Adaptation in natural and artificial systems. Ann Arbor, MI: University of Michigan Press (1975).

Hutson, M., Joutz, F. and Stekler, H. (2014). Interpreting and evaluating CESIfo's World Economic Survey directional forecasts. Economic Modelling, 38, 6-11.

Hyndman, R. J. and Koehler, A. B. (2006). Another look at measures of forecast accuracy. International Journal of Forecasting, 22(4), 679-688.

Ivaldi, M. (1992) Survey evidence on the rationality of expectations. Journal of Applied Econometrics 7(3): 225-241.

Jean-Baptiste, F. (2012). Forecasting with the new Keynesian Phillips curve: Evidence from survey data. Economics Letters, 117(3) 811-813.

Jonsson, T. and Österholm, P. (2011). The forecasting properties of survey-based wage-growth expectations. Economics Letters 113(3): 276-281.

Jonsson, T. and Österholm P. (2012). The properties of survey-based inflation expectations in Sweden. Empirical Economics 42(1): 79-94.

Kaboudan, M. A. (2000). Genetic programing prediction of stock prices. Computational Economics, 16(3), 207-236.

Klein L. R. and Özmucur, S. (2010). The use of consumer and business surveys in forecasting. Economic Modelling, 27(6), 1453-1462.

Klúčik, M. (2012). Estimates of foreign trade using genetic programming. Proceedings of the 46 the scientific meeting of the Italian Statistical Society.

Kotanchek, M. E, Vladislavleva, E. Y. and Smits, G. F. (2010). Symbolic regression via genetic programming as a discovery engine: Insights on outliers and prototypes. In R. Riolo et al., (Eds.), Genetic Programming Theory and Practice VII, Genetic and Evolutionary Computation Vol. 8 (pp. 55-72). Springer Science+Business Media, LLC.

Koza, J. R. (1992). Genetic programming: On the programming of computers by means of natural selection. Cambridge, MA: MIT Press.

Kronberger, G., Fink, S., Kommenda, M. and Affenzeller, M. (2011). Macro-economic time series modeling and interaction networks. In C. Di Chio et al. (Eds.), EvoApplications, Part II (pp. 101-110). LNCS 6625.

Kudymowa, E., Plenk, J. and Wohlrabe, K. (2013). Ifo World Economic Survey and the business cycle in selected countries. CESifo Forum 14 (4): 51-57.

Lacová, Ž. and Král, P. (2015). Measurement and characteristics of enterprise inflation expectations in Slovakia. Procedia Economics and Finance 30: 505-512.

Lahiri, K. and Teigland, C. (1987). On the normality of probability distributions of inflation and GNP forecasts. International Journal of Forecasting 3(2): 269-279.

Lahiri, K. and Zhao, Y. (2015). Quantifying survey expectations: A critical review and generalization of the Carlson-Parkin method. International Journal of Forecasting 31(1): $51-62$.

Larkin, F. and Ryan, C. (2008). Good news: Using news feeds with genetic programming to predict stock prices. In M. O’Neil et al. (Eds.), Genetic Programming (pp. 49-60). Berlin: Springer-Verlag.

Lawrenz, C. and Westerhoff, F. (2003). Modeling exchange rate behaviour with a genetic algorithm. Computational Economics 21(3): 209-229.

Leduc, S. and Sill, K. (2013). Expectations and economic fluctuations: An analysis using survey data. The Review of Economic and Statistics 95(4): 1352-1367.

Lee, K. C. (1994) Formation of price and cost inflation expectations in British manufacturing industries: A multi-sectoral analysis. The Economic Journal 104(423): 372-385. 
Lemmens, A., Croux, C. and Dekimpe, M. G. (2005). On the predictive content of production surveys: A pan-European study. International Journal of Forecasting 21(2): 363-375.

Löffler, G. (1999). Refining the Carlson-Parkin method. Economics Letters 64(2): 167-71.

Lui, S., Mitchell, J. and Weale, M. (2011a). The utility of expectational data: firm-level evidence using matched qualitative-quantitative UK surveys. International Journal of Forecasting 27(4): 1128-1146.

Lui, S., Mitchell, J. and Weale, M. (2011b). Qualitative business surveys: signal or noise? Journal of The Royal Statistical Society, Series A (Statistics in Society) 174(2): 327-348.

Łyziak, T. and Mackiewicz-Łyziak, J. (2014). Do consumers in Europe anticipate future inflation? Eastern European Economics 52(3): 5-32.

Maag, T. (2009). On the accuracy of the probability method for quantifying beliefs about inflation. KOF Working Papers, No. 230. Zurich: KOF Swiss Economic Institute.

Martinsen, K., Ravazzolo, F. and Wulfsberg, F. (2014). Forecasting macroeconomic variables using disaggregate survey data. International Journal of Forecasting 30(1): 65-77.

Maschek, M. K. (2010). Intelligent mutation rate control in an economic application of genetic algorithms. Computational Economics 35(1): 25-49.

Mitchell, J., Smith, R. and Weale, M. (2002). Quantification of qualitative firm-level survey data. Economic Journal 112(478): 117-135.

Mitchell, J., Smith, R. and Weale, M. (2005a). Forecasting manufacturing output growth using firm-level survey data. The Manchester School 73(4): 479-499.

Mitchell, J., Smith, R. and Weale, M. (2005b). An indicator of monthly GDP and an early estimate of quarterly GDP growth. The Economic Journal 115(501): F108-F129.

Mittnik, S. and Zadrozny, P. (2005). Forecasting quarterly German GDP at monthly intervals using monthly IFO business conditions data (2005). In J. E. Sturm and T. Wollmershäuser (Eds.), IFO survey data in business cycle analysis and monetary policy analysis (pp. 1948). Heidelberg: Physica-Verlag.

Mokinski, F., Sheng, X. and Yang, J. (2015). Measuring disagreement in qualitative expectations. Journal of Forecasting 34(5): 405-426.

Müller, C. (2010). You CAN Carlson-Parkin. Economics Letters 108(1): 33-35.

Nardo, M. (2003). The quantification of qualitative data: a critical assessment. Journal of Economic Surveys 17(5): 645-668.

Nardo, M. and Cabeza-Gutés, M. (1999). The role of measurement error in rational expectations testing. UAB Working Paper 451. Barcelona: Universitat Autònoma de Barcelona.

Nolte, I. and Pohlmeier, W. (2007). Using forecasts of forecasters to forecast. International Journal of Forecasting 23(1): 15-28.

Paloviita, M. (2006). Inflation dynamics in the euro area and the role of expectations. Empirical Economics 31: 847-860.

Parigi, G. and Schlitzer, G. (1995). Quarterly forecasts of the Italian business-cycle by means of monthly economic indicators. Journal of Forecasting 14(2): 117-141.

Peng, Y., Yuan, C., Qin, X., Huang, J. and Shi, Y. (2014). An improved gene expression programming approach for symbolic regression problems. Neurocomputing 137: 293301.

Pesaran, M. H. (1985). Formation of inflation expectations in British manufacturing industries. Economic Journal 95(380): 948-975.

Pesaran, M. H. (1987). The limits to rational expectations. Oxford: Basil Blackwell.

Pesaran, M. H. and Weale, M. (2006). Survey Expectations. In G. Elliott, C. W. J. Granger, and A. Timmermann (Eds.), Handbook of Economic Forecasting, Vol. 1 (pp. 715-776). Amsterdam: Elsevier North- Holland.

Poli, R., Vanneschi, L., Langdon, W. B. and Mcphee, N. F. (2010). Theoretical results in genetic programming: The Next Ten Years? Genetic Programming and Evolvable Machines 11(3): 285-320.

Qiao, Z., McAleer, M. and Wong, W. K. (2009). Linear and nonlinear causality between changes in consumption and consumer attitudes. Economic Letters 102(3): 161-164.

Robinzonov et al. (2012)

Sarradj, E. and Geyer, T. (2014). Symbolic regression modeling of noise generation at porous airfoils. Journal of Sound and Vibration 333(14): 3189-3202. 
Schmeling, M. and Schrimpf, A. (2011). Expected inflation, expected stock returns, and money illusion: What can we learn from survey expectations. European Economic Review 55(5): 702-719.

Seitz, H. (1988). The estimation of inflation forecasts from business survey data. Applied Economics 20(4): 427-38.

Smith, J. and McAleer, M. (1995). Alternative procedures for converting qualitative response data to quantitative expectations: an application to Australian manufacturing. Journal of Applied Econometrics 10(2): 165-185.

Terai, A. (2009). Measurement error in estimating inflation expectations from survey data: an evaluation by Monte Carlo simulations. Journal of Business Cycle Measurement and Analysis 8(2): 133-156.

Theil, H. (1952). On the time shape of economic microvariables and the Munich Business Test. Revue de l'Institut International de Statistique 20: 105-20.

Thinyane, H. and Millin, J. (2011). An investigation into the use of intelligent systems for currency trading. Computational Economics 37(4): 363-374.

Vasilakis, G. A., Theofilatos, K. A., Georgopoulos, E. F., Karathanasopoulos, A., and Likothanassis, S. D. (2013). A genetic programming approach for EUR/USD exchange rate forecasting and trading. Computational Economics 42(4): 415-431.

Vladislavleva, E.; Smits, G. and den Hertog, D. (2010). On the importance of data balancing for symbolic regression. IEEE Transactions in Evolutionary Computation 14(2): 252-277.

Vermeulen, P. (2014). An evaluation of business survey indices for short-term forecasting: Balance method versus Carlson-Parkin method. International Journal of Forecasting 30(4): 882-897.

Visco, I. (1984). Price expectations in rising inflation. Amsterdam: North-Holland.

Wei, L. Y. (2013). A hybrid model based on ANFIS and adaptive expectation genetic algorithm to forecast TAIEX. Economic Modelling 33: 893-899.

Wilson, G. and Banzhaf, W. (2009). Prediction of interday stock prices using developmental and linear genetic programming. In M. Giacobini et al. (Eds.), Applications of Evolutionary Computing (pp. 172-181). Berlin: Springer-Verlag.

Wren-Lewis, S. (1986). An econometric model of U.K. manufacturing employment using survey data on expected output. Journal of Applied Econometrics 10(2): 165-185.

Wu, C. H., Chou, H. J. and Su, W. H. (2008). Direct transformation of coordinates for GPS positioning using the techniques of genetic programming and symbolic regression. Engineering Applications of Artificial Intelligence 21(8): 1347-1359.

Yang, G., Li, X., Wang, J., Lian, L. and Ma, T. (2015). Modeling oil production based on symbolic regression. Energy Policy 82(1): 48-61.

Yao, L. and Lin, C. C. (2009). Identification of nonlinear systems by the genetic programmingbased volterra filter. IET Signal Processing 3(2): 93-105.

$\mathrm{Yu}, \mathrm{T}$., Chen, S. and Kuo, T. W. (2004). A genetic programming approach to model international short-term capital flow. Applications of Artificial Intelligence in Finance and Economics 19: 45-70.

Zameer, A., Arshad, J., Khan, A., and Raja, M. A. Z. (2017). Intelligent and robust prediction of short term wind power using genetic programming based ensemble of neural networks. Energy Conversion and Management 134: 361-372.

Zelinka, I., Oplatkova, Z., and Nolle, L. (2005). Analytic programming - Symbolic regression by means of arbitrary evolutionary algorithms. International Journal of Simulation: Systems, Science and Technology 6(9): 44-56.

Zimmermann, K. F. (1997). Analysis of business surveys. In M. H. Pesaran and P. Schmidt (Eds.), Handbook of Applied Econometrics. Volume II: Microeconomics (pp. 407-441), Oxford: Blackwell Publishers. 


\section{$\underset{\oplus}{\mathbb{Q}}|\mathrm{R}| \mathrm{E}|\mathrm{A}|$}

Institut de Recerca en Economia Aplicada Regional i Públic

Research Institute of Applied Economics

WEBSITE: www.ub-irea.com • CONTACT: irea@ub.edu

\section{AQR}

Grup de Recerca Anàlisi Quantitativa Regional

Regional Quantitative Analysis Research Group

WEBSITE: www.ub.edu/aqr/•CONTACT: aqr@ub.edu

\section{Universitat de Barcelona}

Av. Diagonal, 690 • 08034 Barcelona 